\title{
Performance of corn leaf aphid, Rhopalosiphum maidis (Fitch) (Homoptera: Aphididae) on selected maize hybrids under laboratory conditions
}

\author{
Jabraeil RAZMJOU* and Ali GolizAdEH \\ Department of Plant Protection, Faculty of Agriculture, University of Mohaghegh Ardabili; Ardabil, Iran
}

(Received 23 September 2009; Accepted 5 January 2010)

\begin{abstract}
The corn leaf aphid, Rhopalosiphum maidis (Fitch) is one of the most important pests of maize with worldwide distribution. The use of relatively resistant corn hybrids may lessen the harmful effects by this aphid; we therefore compared population growth parameters of $R$. maidis reared on six commonly grown maize hybrids in Iran, namely K3640/3 ×MO17, Simon, SC704, EXP1, VRE26×K18 and VRE27×K18. The experiments were carried out under conditions of $25 \pm 1^{\circ} \mathrm{C}, 60 \pm 10 \% \mathrm{RH}$, and a photoperiod of $16 \mathrm{~L} 8 \mathrm{D}$. The development time and survival of aphid nymphs differed significantly among the maize hybrids tested. We also observed significant differences in aphid fecundity, resulting in large variations in population growth parameters, such as the intrinsic rate of natural increase $\left(r_{m}\right)$, net reproductive rate $\left(R_{0}\right)$, finite rate of increase $(\lambda)$ and doubling time (DT). The $r_{m}$ values were highest for aphids reared on maize hybrids EXP1 and VRE27 $\times$ K18, lowest for aphids reared on hybrid K3640/3 $\times$ MO17, and intermediate for aphids reared on hybrids VRE26×K18, SC704 and Simon. Consequently, these results may offer useful information for planning a comprehensive program for IPM of the corn leaf aphid in Iran.
\end{abstract}

Key words: Rhopalosiphum maidis; population parameters; maize hybrid; plant resistance

\section{INTRODUCTION}

The corn leaf aphid, Rhopalosiphum maidis (Fitch) (Homoptera: Aphididae), is a serious pest of maize with Asiatic origin but it is now distributed throughout the tropics and temperate regions of the world (Hill, 1987; Blackman and Eastop, 2000; Al-Eryan and El-Tabbakh, 2004; Kuo et al., 2006). This aphid is a polyphagous pest and can cause damage to many host plants species and weeds from Gramineae and occasionally Cyperaceae and Typhaceae. Rhopalosiphum maidis damages its host plants by feeding, viral disease transmission and honeydew production. Aphid infestation occurs on seedlings, leaves, inside the whorl, the covers inflorescence of plants and produces plentiful honeydew (Hill, 1987; Bing et al., 1991; Blackman and Eastop, 2000; Gonzáles et al., 2001), which may result in deformed leaves as well as the sterilization of inflorescences (Hill, 1987). In addition, $R$. maidis is a vector of plant viruses and may transmit 10 viral diseases to cereals (Hill,
1987; Blackman and Eastop, 2000).

Maize is an economically important crop in Iran and worldwide and is planted on nearly 300,000 ha annually (planted in 2006-2007). Few insect pests have been found to attack maize fields in Iran. Among these pests, the corn leaf aphid is prevalent in commercial fields of maize (Khanjani, 2005; our personal observations). Outbreaks of this aphid occur in the late growing season, when maize tassels appear. At this time, pesticide applications are generally no longer employed in maize fields; therefore, after this time, aphid control is necessary to produce a high yield of this crop. As is known, pesticide applications have several harmful influences, such as environmental and agroecosystems pollution, being detrimental to human health, as well as financial issues. Moreover, in recent decades, the resistance of different pest species against chemical compounds has considerably increased in the world (e.g., Maklakov et al., 2001; Nauen and Denholm, 2005; Bielza, 2008; Saleem et al., 2008). To suppress these destructive effects,

* To whom correspondence should be addressed at: E-mail: Razmjou@uma.ac.ir DOI: $10.1303 /$ aez.2010.267 
some scientists are endeavoring to find alternative safe procedures for pest control in the fields, which do not have such negative impacts on the environment.

Improving plant resistance is one of the most important integrated pest management techniques, and it has good prospects to decrease dependence on pesticide applications in agroecosystems (e.g., Robinson et al., 1991; Webster et al., 1991; Weathersbee and Hardee, 1994; Li et al., 2004). In addition, host plant quality, typically a major determinant of pest performance, influences the growth and fecundity of herbivorous insects on both individual and population scales (Awmack and Leather, 2002). Plants such as corn vary in morphological characteristics, nutritional values and secondary metabolites. These traits can influence the survival, development, and fecundity of aphids (Weathersbee and Hardee, 1994; Cisneros and Godfrey, 2001; Tsai and Wang, 2001). Low quality as a host can be regarded as a defense mechanism against herbivorous pests in plants, which reduces their fecundity and increases their immature developmental time (Legrand and Barbosa, 2000). Moreover, in order to make accurate decisions in integrated pest management (IPM), it is also necessary to determine pest population growth parameters on different host species, varieties and hybrids. The life table technique represents a very informative means to appraise the fitness of herbivores and resistance levels of host plants, respectively, in various pest insects (Robinson et al., 1991; Hesler et al., 1999; Tsai and Wang, 2001; Satar and Yokomi, 2002; Razmjou et al., 2006; Silva et al., 2006). For example, aphid populations feeding on resistant plants, even moderately resistant, exhibit significantly lower values of $r_{m}$ than populations feeding on susceptible cultivars and plant species. Maize is an economically significant crop, of which numerous hybrids are available commercially. These hybrids may differ in their quality as hosts for $R$. maidis, which is important information for resistance breeding and IPM programs. On the other hand, the use of resistant cultivars is restricted to the regional level, due to the existence of biotypes in the aphids (Puterka et al., 1992; Silva et al., 2006). However, despite the importance of the corn leaf aphid in the maize fields of Iran (Khanjani, 2005), the bionomics of this aphid, particularly on various corn hybrids, has not been identified and its population development traits are unknown in the maize agroecosystem conditions of Iran. Hence, we need to evaluate the demographic parameters of this aphid even on a local scale on available corn hybrids to introduce more resistant hybrids to producers.

Therefore, the main propose of this study was to clarify the population growth attributes of $R$. maidis on six corn hybrids that might differ in supporting the populations of this aphid. These issues might have an important role to reduce outbreaks of the corn leaf aphid under integrated pest management strategies.

\section{MATERIALS AND METHODS}

Plant rearing and hybrid selection. Six maize (Zea mays L.) hybrids, namely K3640/3×MO17 (a late maturing maize hybrid from Iran), Simon (a late maturing maize hybrid from Turkey), SC704 (a late maturing maize hybrid commonly grown in Iran), EXP1 (similar to a late maturing maize hybrid, probably from Greece), VRE26×K18 (a late maturing maize hybrid from Iran) and VRE27X K18 (a late maturing maize hybrid from Iran) were used for this study. The hybrids were a selection of those already employed in a previous study in the Moghan region, Ardabil province, Iran (our unpublished data; European corn stem borer study) by our research team in the region. We estimated the status of aphid infestations on each corn hybrid based on visual observations only.

The seeds of corn hybrids used in this study were obtained from the Seed and Plant Improvement Institute of Karaj, Iran and were sown in 25$\mathrm{cm}$ plastic pots filled with appropriate field soil. Plants were reared at $25 \pm 5^{\circ} \mathrm{C}, 60 \pm 10 \% \mathrm{RH}$ and a photoperiod of (approximately) 14L10D with ambient light in a greenhouse. To establish plant materials for conducting each experiment, fresh corn leaf pieces $(4 \times 5 \mathrm{~cm})$ from the top of about twomonth-old corn seedlings were cut and placed on water-saturated cotton in a Petri dish $(90 \mathrm{~mm}$ in diameter, $10 \mathrm{~mm}$ in height) to prevent desiccation of the leaves and aphids. Before using the leaves in the experiments, they were checked and cleaned of aphids and other pests if required. We replaced the excised leaves every 4-5 days with fresh corn leaves as described previously (Kuo et al., 2006; Razmjou et al., 2009). 
Aphid culture. First, in September 2008, the aphids used in the experiments were collected from a corn field in the Research Station, Faculty of Agriculture (Babelan Research Station), University of Mohaghegh Ardabili, Ardabil, Iran. Colonies were established on corn seedlings of hybrid VRE26 $\times$ K18 in the greenhouse according to the procedure described above. The aphid population was reared for at least one month before experiments were initiated.

Experiments. All experiments were conducted in a growth chamber at $25 \pm 1{ }^{\circ} \mathrm{C}, 60 \pm 10 \% \mathrm{RH}$ and a photoperiod of 16L8D. On October 23, 2008, to evaluate the developmental time and survival of immature stages, fecundity and adult longevity, adult apterous aphids were randomly selected from the rearing colonies and placed on the detached leaf surface inside each Petri dish, as described above using a fine-hair brush. They were then permitted to produce nymphs for 24 hours. After one day (October 24, 2008), the adults were removed and only a cohort of three or four newly born nymphs was maintained together in each Petri dish for determining nymphal biological parameters (Razmjou et al., 2006; Zhang et al., 2008). These remaining nymphs were monitored daily until reaching adulthood to assess the developmental time and survival of nymphs on all hybrids. In this step, we assessed the development and survival rate of 53-67 nymphs per maize hybrid (Table 1). After maturity and the beginning of reproduction, we selected and transferred only one newly emerged adult aphid to another new Petri dish with a fresh corn leaf placed on water-saturated cotton, as mentioned above. The mortality and fecundity of these apterous aphids were recorded and offspring were removed from each Petri dish daily until the death of the adult aphid. In this way, we evaluated the fecundity of 19-22 adult aphids per maize hybrid (see Table 1). The experiments were performed during 2008 in the laboratory, College of Agriculture, University of Mohaghegh Ardabili, Ardabil, Iran.

Life table parameters. The survival of apterous aphids and each nymph was monitored and recorded in 24-h periods. The survival of adults and nymphs as well as the longevity and fecundity of each apterous aphid was determined on the six hybrids tested. We calculated the intrinsic rate of natural increase $\left(r_{m}\right)$ of apterous aphids on different corn hybrids according to the equation given by Birch (1948) as follows:

$$
\sum e^{-r x} l_{x} m_{x}=1
$$

Furthermore, the net reproductive rate $\left(R_{0}=\right.$ $\left.\sum l_{x} m_{x}\right)$, mean generation time $\left(T=\ln R_{0} / r\right)$, doubling time (DT), and finite rare of increase $\left(\lambda=e^{r}\right)$ for corn leaf aphid on corn hybrids examined were calculated, where $x$ is the age in days, $r$ is the intrinsic rate of natural increase, $l_{x}$ is the proportion of living females on a given day, and $m_{x}$ is the mean number of female offspring produced on the same day (Southwood, 1978; Carey, 1993).

Table 1. Developmental time, reproductive period, mean number of nymphs per aphid per day, adult longevity and mean nymphs per female of Rhopalosiphum maidis reared on six maize hybrids at $25^{\circ} \mathrm{C}$

\begin{tabular}{|c|c|c|c|c|c|c|c|}
\hline \multirow{2}{*}{ Hybrids } & \multicolumn{7}{|c|}{ Parameters $(\text { mean } \pm \mathrm{SE})^{\mathrm{a}}$} \\
\hline & $\begin{array}{l}\text { Developmental } \\
\text { time (d) }\end{array}$ & $\begin{array}{c}\text { Nymphal } \\
\text { survival (\%) }\end{array}$ & $n^{\mathrm{b}}$ & $\begin{array}{l}\text { Reproductive } \\
\text { period (d) }\end{array}$ & $\begin{array}{l}\text { Mean number of } \\
\text { nymphs/aphid/d }\end{array}$ & $\begin{array}{c}\text { Adult } \\
\text { longevity (d) }\end{array}$ & Fecundity $^{c}$ \\
\hline $\mathrm{K} 3640 / 3 \times \mathrm{MO} 17$ & $7.9 \pm 0.1$ a (66) & $40.9(66)$ & 20 & $8.3 \pm 0.8 \mathrm{~b}$ & $2.4 \pm 0.2 \mathrm{~b}$ & $10.6 \pm 1.1 \mathrm{a}$ & $19.6 \pm 2.1 \mathrm{~b}$ \\
\hline Simon & $7.2 \pm 0.1 \mathrm{~b}(63)$ & $47.8(63)$ & 21 & $9.5 \pm 1.3 \mathrm{ab}$ & $2.6 \pm 0.2 \mathrm{~b}$ & $11.2 \pm 1.4 \mathrm{a}$ & $24.0 \pm 3.5 \mathrm{~b}$ \\
\hline SC704 & $8.0 \pm 0.2$ a (56) & $51.8(56)$ & 22 & $10.2 \pm 1.1 \mathrm{ab}$ & $3.0 \pm 0.3 \mathrm{ab}$ & $13.2 \pm 1.4 \mathrm{a}$ & $31.4 \pm 4.3 \mathrm{ab}$ \\
\hline EXP1 & $7.8 \pm 0.1$ a $(53)$ & $56.6(53)$ & 19 & $12.1 \pm 0.9 \mathrm{ab}$ & $3.9 \pm 0.2 \mathrm{a}$ & $15.1 \pm 1.2 \mathrm{a}$ & $46.5 \pm 4.2 \mathrm{a}$ \\
\hline VRE26×K18 & $7.5 \pm 0.2 \mathrm{ab}(57)$ & $57.9(57)$ & 22 & $13.1 \pm 1.3 \mathrm{a}$ & $3.1 \pm 0.3 \mathrm{ab}$ & $15.5 \pm 1.5 \mathrm{a}$ & $39.8 \pm 4.8 \mathrm{a}$ \\
\hline VRE27×K18 & $7.1 \pm 0.1 \mathrm{~b}(67)$ & $62.6(67)$ & 21 & $10.5 \pm 1.0 \mathrm{ab}$ & $3.1 \pm 0.3 \mathrm{ab}$ & $12.9 \pm 1.3 \mathrm{a}$ & $31.5 \pm 3.6 \mathrm{ab}$ \\
\hline
\end{tabular}

\footnotetext{
${ }^{a}$ For each parameter, differences between maize hybrids were determined by Tukey-Kramer test. Within columns, means followed by the same letters are not significantly different $(p>0.05)$.

${ }^{\mathrm{b}}$ The $n$ value shows the sample size of each parameter. Only the numbers of nymphs tested for developmental time and nymphal survival are given in parentheses.

${ }^{\mathrm{c}}$ Fecundity is the mean number of nymphs/female.
} 
Statistical analysis. We estimated the following life history traits: developmental time and survival of the nymphal stage, adult longevity, and fecundity. Data on these parameters were analyzed by analysis of variance (ANOVA) using the SAS GLM procedure (PROC GLM; SAS Institute, 1989). When the mean values demonstrated significant differences among treatments, they were separated using the Tukey-Kramer test at $\alpha=0.05$ (SAS Institute, 1989). Also, life table parameters, including the intrinsic rate of natural increase $\left(r_{m}\right)$, net reproductive rate $\left(R_{0}\right)$, doubling time (DT), finite rate of increase $(\lambda)$, and the mean generation time $(T)$, were calculated by the jackknife method (Meyer et al., 1986; Carey, 1993) using Maia's program written for the SAS System (SAS Institute, 1989; Maia et al., 2000). The pseudo-values of life table parameters calculated by Maia's program were subjected to analysis of variance using PROC GLM (PROC GLM; SAS Institute, 1989). When the analysis of variance of these parameters indicated significant differences between the hybrids tested, the means of treatments were compared by the Tukey-Kramer test at $\alpha=0.05$ (SAS Institute, 1989).

\section{RESULTS}

The results obtained in experiments on biological attributes, including nymphal mortality, developmental time of immature stages, adult longevity and fecundity, as well as life table characteristics of $R$. maidis, are presented in Tables 1 and 2, respectively.

\section{Developmental time and survival}

The developmental time of nymphs was significantly affected by corn hybrids $(F=7.15 ; \mathrm{df}=5$, $119 ; p<0.001)$. The values for developmental time ranged from 7.1 to 8.0 days on the six hybrids. The developmental time of $R$. maidis nymphs was lowest on VRE $27 \times$ K18 and highest on SC704 (Table $1)$. The percentages $(\%)$ of nymphal stages surviving to adulthood ranged from 40.9 to 62.6 on K3640/3 $\times$ MO17 and VRE27 $\times$ K18 corn hybrids examined, respectively (Table 1).

\section{Adult longevity and fecundity}

There were no significant differences in adult longevity of $R$. maidis reared on the corn hybrids examined $(F=2.17$; $\mathrm{df}=5,119 ; p=0.062$; Table 1$)$.

Corn leaf aphid fecundity also differed significantly among the corn hybrids tested $(F=6.26$; $\mathrm{df}=5,119 ; p<0.001)$. Aphid fecundity was lowest on K3640/3 $\times$ MO17 and highest on EXP1 hybrids (Table 1). In addition, the mean number of nymphs per female per day of $R$. maidis was significantly affected by corn hybrids $(F=4.25$; df $=5,119$; $p=0.001$ ). Aphids reared on the EXP1 hybrid produced the highest mean number of nymphs per female per day, whereas aphids reared on K3640/ $3 \times \mathrm{MO} 17$ produced the lowest number of offspring per day (Table 1; Fig. 1).

The reproductive period of the corn leaf aphid significantly varied among corn hybrids $(F=2.52$; $\mathrm{df}=5,119 ; p=0.033$; Table 1).

\section{Life table statistics}

The $r_{m}$ values of viviparous apterae of $R$. maidis

Table 2. Life table attributes of Rhopalosiphum maidis reared on six maize hybrids at $25^{\circ} \mathrm{C}$

\begin{tabular}{|c|c|c|c|c|c|c|}
\hline \multirow{2}{*}{ Hybrids } & \multicolumn{6}{|c|}{$\operatorname{Parameters}^{\mathrm{a}}($ mean $\pm \mathrm{SE})$} \\
\hline & $n^{\mathrm{b}}$ & $\begin{array}{l}\text { Net reproductive } \\
\text { rate }\left(R_{0}\right)\end{array}$ & $\begin{array}{l}\text { Intrinsic rate of } \\
\text { increase }\left(r_{m}\right)\end{array}$ & $\begin{array}{c}\text { Mean generation } \\
\text { time }(T)\end{array}$ & $\begin{array}{l}\text { Doubling time } \\
\text { (DT) }\end{array}$ & $\begin{array}{l}\text { Finite rate of } \\
\text { increase }(\lambda)\end{array}$ \\
\hline $\mathrm{K} 3640 / 3 \times \mathrm{MO} 17$ & 20 & $8.6 \pm 0.2 \mathrm{~d}$ & $0.209 \pm 0.002 \mathrm{c}$ & $10.3 \pm 0.1 \mathrm{ab}$ & $3.3 \pm 0.0 \mathrm{a}$ & $1.232 \pm 0.002 \mathrm{c}$ \\
\hline Simon & 21 & $12.1 \pm 0.4 \mathrm{~cd}$ & $0.245 \pm 0.002 \mathrm{bc}$ & $10.2 \pm 0.1 \mathrm{~b}$ & $2.8 \pm 0.0 \mathrm{~b}$ & $1.278 \pm 0.003 \mathrm{bc}$ \\
\hline SC704 & 22 & $17.3 \pm 0.5 \mathrm{bc}$ & $0.254 \pm 0.002 \mathrm{~b}$ & $11.2 \pm 0.1 \mathrm{ab}$ & $2.7 \pm 0.0 \mathrm{bc}$ & $1.289 \pm 0.003 \mathrm{~b}$ \\
\hline EXP1 & 19 & $27.3 \pm 0.5 \mathrm{a}$ & $0.299 \pm 0.002 \mathrm{a}$ & $11.1 \pm 0.1 \mathrm{ab}$ & $2.3 \pm 0.0 \mathrm{c}$ & $1.348 \pm 0.002 \mathrm{a}$ \\
\hline VRE $26 \times K 18$ & 22 & $24.1 \pm 0.6 \mathrm{ab}$ & $0.268 \pm 0.002 \mathrm{ab}$ & $11.9 \pm 0.1 \mathrm{a}$ & $2.6 \pm 0.0 \mathrm{bc}$ & $1.308 \pm 0.003 \mathrm{ab}$ \\
\hline VRE27×K18 & 21 & $20.8 \pm 0.5 \mathrm{ab}$ & $0.293 \pm 0.002 \mathrm{a}$ & $10.4 \pm 0.1 \mathrm{ab}$ & $2.4 \pm 0.0 \mathrm{c}$ & $1.341 \pm 0.003 \mathrm{a}$ \\
\hline
\end{tabular}

\footnotetext{
${ }^{\text {a }}$ For each parameter, differences between maize cultivars were determined by Tukey-Kramer test. Within columns, means followed by the same letters are not significantly different $(p>0.05)$.

${ }^{\mathrm{b}}$ The $n$ value shows the number of aphids tested for each parameter.
} 

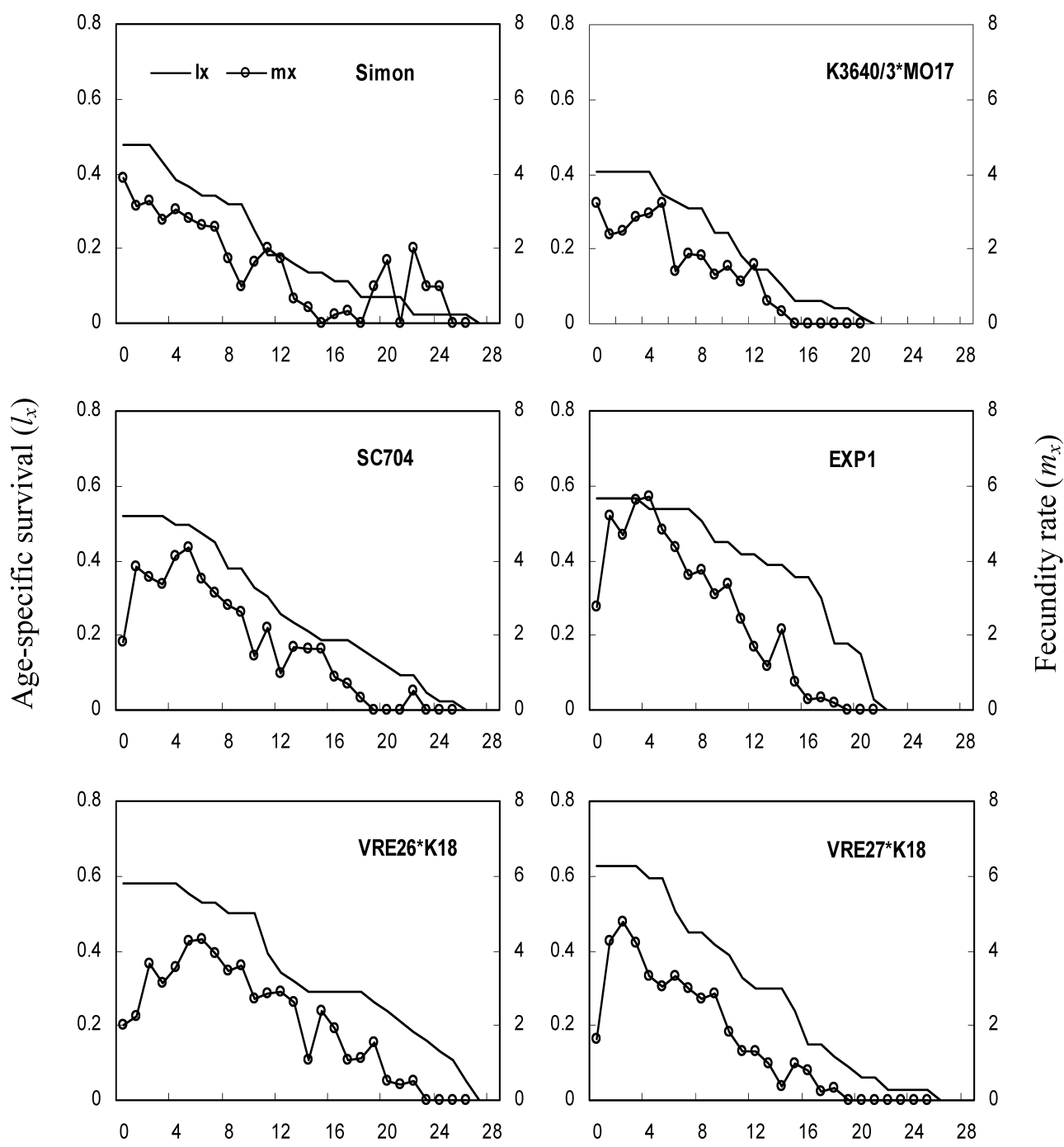

Age (day)

Fig. 1. Age-specific survival $\left(l_{x}\right)$ (adult stage) and fecundity rate $\left(m_{x}\right)$ of Rhopalosiphum maidis reared on six maize hybrids at $25^{\circ} \mathrm{C}$.

differed significantly among the six maize hybrids tested $(F=11.28 ; \mathrm{df}=5,119 ; p<0.001)$. The $r_{m}$ values of aphids reared on maize hybrids EXP1 and VRE27 $\times$ K18 were highest, $r_{m}$ values of aphids reared on hybrid K3640/3×MO17 were lowest, while aphids reared on hybrids VRE26×K18, SC704 and Simon achieved intermediate values of $r_{m}$ (Table 2). In addition, significant variation in the net reproductive rate $\left(R_{0}\right)$ values of maize leaf aphid was observed among hybrids of maize $(F=11.36 ; \mathrm{df}=5,119 ; p<0.001)$. The aphids reared on EXP1 showed the highest $R_{0}$ values and those on $\mathrm{K} 3640.3 \times \mathrm{MO} 17$ achieved the lowest $R_{0}$ values (Table 2). The finite rate of in- crease $(\lambda)$ and the doubling time (DT) varied in a comparable pattern and displayed the same hierarchy of performance: best on EXP1, followed by VRE27 $\times$ K18, VRE26 $\times$ K18, SC704 and Simon, and worst on $\mathrm{K} 3640 / 3 \times \mathrm{MO} 17$ (Table 2).

\section{DISCUSSION}

Our results revealed substantial variation in $R$. maidis development and fecundity on a range of maize hybrids. Under the laboratory conditions used, the performance of $R$. maidis on different corn hybrids was similar for some traits, such as adult longevity, but differed significantly for oth- 
ers, such as nymphal development and the mean reproduction periods, lifetime and daily fecundity. The $r_{m}$ values of the corn leaf aphid, as a good indicator of insect population growth, ranged from 0.209 to $0.299 \mathrm{females} /$ female/day. The findings of Kuo et al. (2006) demonstrated that the highest population build-up potential of $R$. maidis occurs at around $25^{\circ} \mathrm{C}$, resulting in the maximum $r_{m}$ of this aphid (0.329, nymphs/aphid/day) at that temperature. Of the six hybrids tested in the present study, EXP1 and VRE27 $\times \mathrm{K} 18$ can be classified as the most suitable hosts for the corn leaf aphid. In contrast, an increased developmental time and reduced longevity as well as fecundity on K3640/3 $\times$ MO17 as a relatively unsuitable host would reduce the development and spread of $R$. maidis and subsequently increase the opportunity for predators and parasitoids attacks. Significant differences in aphid biological traits among the six tested hybrids of corn indicate at least feasible antibiotic mechanisms for resistance to corn leaf aphid in maize; however, the source of these disparities in the population growth characteristics of $R$. maidis on different corn hybrids tested here is unknown and needs to be investigated.

In Iran, especially in corn-growing areas of Moghan, $R$. maidis populations reappear at high density in midsummer towards the end of the growing season on the terminal parts of corn plants (leaves and inflorescences), with the population increasing in August and September, when the majority of feeding damage occurs (Kuo et al., 2006; our personal observations). Several factors might be responsible for this phenomenon. First, pesticide applications in corn fields have been discontinued and aphid populations therefore increase in the absence of pesticides. Second, climatic conditions (e.g., at the most appropriate temperature and relative humidity) for aphid increase are very favorable in late summer in the region. Bing et al. (1991) reported that corn leaf aphids attack maize in coleoptiles and at two/four leaf stages, and decrease its growth and height with ensuing pollen fall and hindrance of plant silking. Several aphid species, such as Aphis gossypii (Razmjou et al., 2006; Zamani et al., 2006), R. padi (Asin and Pons, 2001), and Aphis fabae Scopoli (Kuroli and Lantos, 2008) display comparable behavior on their hosts. Therefore, decreasing aphid density through the use of hybrids with low supporting aphid popu- lations would be very important both early and late in the corn-growing season.

Plant resistance in maize has been adequately recognized by different researchers (see Smith et al., 1994) and some hybrids have been found to be resistant to its pests. Moreover, the combination of host plant resistance with other methods, including natural enemies, especially coccinellids and cultural control, such as early sowing, has undoubtedly reduced the populations of Aphis craccivora Koch on the cowpea (Ofuya, 1997) and A. fabae on fava bean plants (Shannag and Obeidat, 2008). Accordingly, a two/triple beneficial interaction between these agents would enable comprehensive pest management programs in maize fields; however, additional studies are warranted to elucidate the interactions between diverse constituents that may be successfully integrated within pest management strategies. Consequently, our data presented in this work addressed new information on fecundity and development rates as well as the demographic parameters of $R$. maidis and this knowledge would therefore be helpful to develop an integrated pest management program (IPM) in order to improve production in maize fields.

\section{ACKNOWLEDGMENTS}

The authors would like to thank to the Seed and Plant Improvement Institute of Karaj, Ministry of Agriculture, Iran, for providing the seeds of different maize hybrids tested in this study. We also gratefully acknowledge H. Tavakkoli, A. Fallahi and M. Nemati (from University of Mohaghagh Ardabili) for their valuable help in the experiment. Special thanks to Dr. C. Vorburger of the Institute of Integrative Biology, ETH Zürich, Switzerland \& EAWAG, Swiss Federal Institute of Aquatic Science and Technology, Dübendorf, Switzerland for reviewing and improving an earlier version of this paper. Thanks to Mr. G. Aminzadeh and A. Asadi, the head and assistant (respectively) of the Agricultural and Natural Resources Center, Moghan, Ardabil province for their invaluable help. This work was financially supported by the University of Mohaghegh Ardabili, Arabil, Iran.

\section{REFERENCES}

Al-Eryan, M. A. S. and S. S. El-Tabbakh (2004) Forecasting yield of corn, Zea mays infested with corn leaf aphid, Rhopalosiphum maidis. J. Appl. Entomol. 128: 312-315.

Asin, L. and X. Pons (2001) Effect of high temperature on the growth and reproduction of corn aphids (Homoptera: Aphididae) and implications for their population dynamics on the northeastern Iberian Peninsula. Environ. Entomol. 30: 1127-1134.

Awmack, C. S. and S. R. Leather (2002) Host plant quality 
and fecundity in herbivorous insects. Annu. Rev. Entomol. 47: 817-844.

Bielza, P. (2008) Insecticide resistance management strategies against the western flower thrips, Frankliniella occidentalis. Pest Manag. Sci. 64: 1131-1138.

Bing, J. W., W. D. Guthrie, F. F. Dicke and J. J. Obrycki (1991) Seedling stage feeding by corn leaf aphid (Homoptera: Aphididae): influence on plant development in maize. $J$. Econ. Entomol. 84: 625-632.

Birch, L. C. (1948) The intrinsic rate of increase of an insect population. J. Anim. Ecol. 17: 15-26.

Blackman, R. L. and V. F. Eastop (2000) Aphids on the World's Crops. An Identification and Information Guide. 2nd ed. John Wiley and Sons Ltd., Chichester. 375 pp.

Carey, J. R. (1993) Applied Demography for Biologists. Oxford University Press, NewYork. 206 pp.

Cisneros, J. J. and L. D. Godfrey (2001) Midseason pest status of the cotton aphid (Homoptera: Aphididae) in California cotton: is nitrogen a key factor? Environ. Entomol. 30: 501-510.

Gonzáles, W. L., E. Gianoli and H. M. Niemeyer (2001) Plant quality vs. risk of parasitism: within-plant distribution and performance of the corn leaf aphid, Rhopalosiphum maidis. Agric. For. Entomol. 3: 29-33.

Hesler, L. S., W. E. Riedell, R. W. Kieckhefer, S. D. Haley and R. D. Collins (1999) Resistance to Rhopalosiphum padi (Homoptera: Aphididae) in wheat germplasm accessions. J. Econ. Entomol. 92: 1234-1238.

Hill, D. S. (1987) Agricultural Insect Pests of Temperate Regions and Their Control. Cambridge University Press, London. 659 pp.

Khanjani, M. (2005) Field Crop Pests (Insects and Mites) in Iran. Bu-Ali Sina University Press, Hamadan, Iran. 719 pp. (in Persian).

Kuo, M. H., M. C. Chiu and J. J. Perng (2006) Temperature effects on life history traits of the corn leaf aphid, Rhopalosiphum maidis (Homoptera: Aphididae) on corn in Taiwan. Appl. Entomol. Zool. 41: 171-177.

Kuroli, G. and Z. Lantos (2008) Changes in abundance of aphids flying over and feeding on broad bean in a period of 20 years. Arch. Phytopathol. Plant Protec. 41: 261-272.

Legrand, A. and P. Barbosa (2000) Pea aphid (Hom., Aphididae) fecundity, rate of increase, and within plant distribution unaffected by plant morphology. Environ. Entomol. 29: 987- 993.

Li, Y., C. B. Hill and G. L. Hartman (2004) Effect of three resistant soybean genotypes on the fecundity, mortality, and maturation of soybean aphid (Homoptera: Aphididae). J. Econ. Entomol. 97: 1106-1111.

Maia, A. H. N., A. J. B. Luiz and C. Campanhola (2000) Statistical influence on associated fertility life table parameters using jackknife technique, computational aspects. $J$. Econ. Entomol. 93: 511-518.

Maklakov, A., I. Ishaaya, A. Freidberg, A. Yawetz, A. R. Horowitz and I. Yarom (2001) Toxicological studies of organophosphate and pyrethroid insecticides for controlling the fruit fly Dacus ciliatus (Diptera: Tephritidae). J. Econ. Entomol. 94: 1059-1066.
Meyer, J. S., C. G. Ingersoll, L. L. McDonald and M. S. Boyc (1986) Estimating uncertainty in population growth rates: jackknife vs. bootstrap techniques. Ecology 67: 1156-1166.

Nauen, R. and I. Denholm (2005) Resistance of insect pests to neonicotinoid insecticides: Current status and future prospects. Arch. Insect Biochem. Physiol. 58: 200-215.

Ofuya, T. I. (1997) Control of the cowpea aphid, Aphis craccivora Koch (Homoptera: Aphididae), in cowpea, Vigna unguiculata (L.). Walp Integ. Pest Manag. Rev. 2: 199-207.

Puterka, G. J., J. D. Burd and R. L. Burton (1992) Biotypic variation in a worldwide collection of Russian wheat aphid (Homoptera: Aphididae). J. Econ. Entomol. 85: 1497-1506.

Razmjou, J., S. Moharramipour, Y. Fathipour and S. Z. Mirhoseini (2006) Effect of cotton cultivar on performance of Aphis gossypii (Homoptera: Aphididae) in Iran. $J$. Econ. Entomol. 99: 1820-1825.

Razmjou, J., H. Tavakkoli and A. Fallahi (2009) Effect of soybean cultivar on life history parameters of Tetranychus urticae Koch (Acari: Tetranychidae). J. Pest Sci. 82: 86-92.

Robinson, J., H. E. Vivar, P. A. Burnett and D. S. Calhoun (1991) Resistance to Russian wheat aphid (Homoptera: Aphididae) in barley genotypes. J. Econ. Entomol. 84: 674-679.

Saleem, M. A., M. Ahmad, M. Aslam and A. H. Sayyed (2008) Resistance to selected organochlorin, organophosphate, carbamate and pyrethroid, in Spodoptera litura (Lepidoptera: Noctuidae) from Pakistan. J. Econ. Entomol. 101: 1667-1675.

SAS Institute (1989) Release 8.02. SAS Institute, Cary, NC.

Satar, S. and R. Yokomi (2002) Effect of temperature and host on development of Brachycaudus schwartzi (Homoptera: Aphididae). Ann. Entomol. Soc. Am. 95: 597-602.

Shannag, H. K. and W. M. Obeidat (2008) Interaction between plant resistance and predation of Aphis fabae (Homoptera: Aphididae) by Coccinella septempunctata (Coleoptera: Coccinellidae). Ann. Appl. Biol. 152: 331-337.

Silva, A. D. A., E. M. Varanda and J. R. Barosela (2006) Resistance and susceptibility of alfalfa (Medicago sativa L.) cultivars to the aphid Therioaphis maculata (Homoptera: Aphididae): insect biology and cultivar evaluation. Insect Sci. 13: 55-60.

Smith, C. M., Z. R. Khan and M. D. Pathak (1994) Techniques for Evaluating Insect Resistance in Crops Plants. Technology and Engineering, CRC Press, Boca Raton, Florida. 320 pp.

Southwood, T. R. E. (1978) Ecological Methods, with Particular Reference to the Study of Insect Populations. Chapman \& Hall, New York. 524 pp.

Tsai, J. H. and J. J. Wang (2001) Effects of host plant on biology and life table parameters of Aphis spiracola (Hom.: Aphididae). Environ. Entomol. 30: 44-50.

Weathersbee III, A. A. and D. D. Hardee (1994) Abundance of cotton aphids and associated biological control agents 
on six cotton cultivars. J. Econ. Entomol. 87: 258-265.

Webster, J. A., C. A. Baker and D. R. Porter (1991) Detection and mechanisms of Russian wheat aphid (Homoptera: Aphididae) resistance in barley. J. Econ. Entomol. 84: 669-673.

Zamani, A. A., A. A. Talebi, Y. Fathipour and V. Baniameri (2006) Effect of temperature on biology and population growth parameters of Aphis gossypii Glover (Hom., Aphi- didae) on greenhouse cucumber. J. Appl. Entomol. 130: 453-460.

Zhang, G. F., F. H. Wan, S. T. Murphy, J. Y. Guo and W. X. Liu (2008) Reproductive biology of two nontarget insect species, Aphis gossypii (Homoptera: Aphididae) and Orius sauteri (Hemiptera: Anthocoridae), on Bt and nonBt cotton cultivars. Environ. Entomol. 37: 1035-1042. 